\title{
The gastrointestinal aspects of halitosis
}

\author{
Sivan Kinberg $M D^{1}$, Miki Stein $\mathrm{MD}^{2}$, Nataly Zion $\mathrm{RN}^{2}$, Ron Shaoul $\mathrm{MD}^{3}$
}

S Kinberg, M Stein, N Zion, R Shaoul. The gastrointestinal aspects of halitosis. Can J Gastroenterol 2010;24(9):552-556.

BACKGROUND: Halitosis is a common human condition for which the exact pathophysiological mechanism is unclear. It has been attributed mainly to oral pathologies. Halitosis resulting from gastrointestinal disorders is considered to be extremely rare. However, halitosis has often been reported among the symptoms related to Helicobacter pylori infection and gastroesophageal reflux disease.

OBJECTIVE: To retrospectively review the experience with children and young adults presenting with halitosis to a pediatric gastroenterology clinic.

METHODS: A retrospective chart review of patients diagnosed with halitosis as a primary or secondary symptom was conducted. All endoscopies were performed by the same endoscopist.

RESULTS: A total of 94 patients had halitosis, and of the 56 patients (59.6\%) who were recently examined by a dental surgeon, pathology (eg, cavities) was found in only one (1.8\%). Pathology was found in only six of 27 patients (28.7\%) who were assessed by an otolaryngology surgeon. Gastrointestinal pathology was found to be very common, with halitosis present in 54 of the $94(57.4 \%)$ patients. The pathology was noted regardless of dental or otolaryngological findings. Most pathologies, both macroscopically and microscopically, were noted in the stomach $(60 \%$ non- $H$ pylori related), followed by the duodenum and the esophagus. Fifty-two of 90 patients $(57.8 \%)$ were offered a treatment based on their endoscopic findings. Of the 74 patients for whom halitosis improvement data were available, some improvement was noted in 24 patients $(32.4 \%)$ and complete improvement was noted in 41 patients $(55.4 \%)$.

CONCLUSIONS: Gastrointestinal pathology was very common in patients with halitosis regardless of dental or otolaryngological findings, and most patients improved with treatment.

Key Words: Duodenitis; Esophagitis; Gastritis; Gastrointestinal; Halitosis; Helicobacter pylori

$\mathrm{H}$ alitosis is a common human condition affecting a large proportion of the population $(1,2)$. The exact pathophysiological mechanism of halitosis is unclear, although it has been attributed mainly to oral pathologies (3). In most cases, it results from microbial activity on the dorsal tongue, and between the teeth and periodontium (3). Outside the oral cavity, halitosis has been associated with chronic sinusitis, upper and lower respiratory tract conditions, various systemic diseases and the use of certain drugs (3). Habitual mouth breathing has been also suggested to be a common cause of halitosis $(2,3)$.

Halitosis resulting from gastrointestinal disorders is considered to be extremely rare because the esophagus is normally collapsed and closed (4). Nevertheless, halitosis has often been reported among the symptoms related to Helicobacter pylori

\section{Les aspects gastro-intestinaux de la mauvaise haleine}

HISTORIQUE : La mauvaise haleine est un trouble humain courant, dont le mécanisme physiopathologique exact est nébuleux. On l'attribue surtout à des pathologies orales. La mauvaise haleine résultant de troubles gastro-intestinaux est considérée comme d'une extrême rareté. Cependant, elle est souvent déclarée dans les symptômes de l'infection à Helicobacter pylori et du reflux gastro-œesophagien pathologique.

OBJECTIF : Procéder à l'analyse rétrospective de l'expérience auprès d'enfants et de jeunes adultes qui avaient consulté à une clinique de gastroentérologie pédiatrique et avaient des problèmes de mauvaise haleine.

MÉTHODOLOGIE : Les chercheurs ont procédé à l'analyse rétrospective des dossiers de patients chez qui on avait diagnostiqué une mauvaise haleine comme symptôme primaire ou secondaire. Toutes les endoscopies ont été effectuées par le même endoscopiste.

RÉSULTATS : Au total, 94 patients avaient mauvaise haleine, et chez les 56 patients $(59,6 \%)$ qui avaient été récemment examinés par un chirurgien dentiste, on n'a décelé une pathologie (p. ex., des caries) chez un seul d'entre eux $(1,8 \%)$. Une telle pathologie avait été constatée chez seulement six des 27 patients ( $28,7 \%$ ) évalués par un chirurgien otorhinolaryngologiste. Les pathologies gastro-intestinales étaient toutefois très courantes, la mauvaise haleine étant présente chez 54 des 94 (57,4 \%) patients, quels que soient les résultats dentaires ou otorhinolaryngologiques. La plupart des pathologies, qu'elles soient macroscopiques ou microscopiques, étaient observées dans l'estomac ( $60 \%$ non liées au $\mathrm{H}$ pylori), suivies du duodénum et de l'œsophage. On a offert un traitement fondé sur les observations endoscopiques à 52 des 90 patients $(57,8 \%)$. Des 74 patients pour qui on possédait des données sur la diminution de la mauvaise haleine, on soulignait une certaine amélioration de ce symptôme chez 24 patients $(32,4 \%)$ et une disparition complète du problème chez 41 patients $(55,4 \%)$.

CONCLUSIONS : Les pathologies gastro-intestinales sont très fréquentes chez les patients ayant mauvaise haleine, quel que soit leur était dentaire ou otorhinolaryngologique, et l'état de la plupart des patients s'est amélioré grâce au traitement.

${ }^{1}$ Pediatric Department, Bnai Zion Medical Center; ${ }^{2}$ Clalit Health Services, Pinsker Clinic, Kiryat-Ata; ${ }^{3}$ Pediatric Gastroenterology and

Nutrition Unit, Meyer Children's Hospital of Haifa, Rambam Medical Center, Rappaport Faculty of Medicine, Technion, Haifa, Israel

Correspondence: Dr Ron Shaoul, Pediatric Gastroenterology and Nutrition Unit, Meyer Children's Hospital of Haifa, Rambam Medical

Center, PO Box 9602, Haifa 31096, Israel. Telephone 972-50-206-3333, fax 972-4-854-1805, e-mail shaoul_r@012.net.il

Received for publication November 14, 2009. Accepted December 24, 2009 
TABLE 1

Patients' general characteristics $(n=94)$

\begin{tabular}{lc}
\hline Demographics & \\
Age, years, mean (range) & $12.4(1.11-38.6)$ \\
Sex, n:n, female/male (\%:\%) & $51: 43(54.3: 45.7)$ \\
Comorbidities & \\
Ear, nose and throat problems & $11(11.7)$ \\
Status post-tonsillectomy/adenoidectomy & $4(4.3)$ \\
Enlarged tonsils/adenoids & $3(3.2)$ \\
Signs of reflux on arytenoids & $2(2.1)$ \\
Sinusitis & $1(1.1)$ \\
Recurrent tonsillitis & $1(1.1)$ \\
Iron deficiency anemia & $6(6.4)$ \\
Asthma & $5(5.3)$ \\
Failure to thrive & $4(4.3)$ \\
Urinary retention/vesicoureteral reflux & $2(2.1)$ \\
Prematurity & $2(2.1)$ \\
Crohn's disease & $2(2.1)$ \\
Hypothyroidism & $1(1.1)$ \\
Milk allergy & $1(1.1)$ \\
Allergies & $1(1.1)$ \\
Deafness & $1(1.1)$ \\
Arthritis & $1(1.1)$ \\
Celiac disease & $1(1.1)$ \\
Attention deficit disorder & $1(1.1)$ \\
Obesity & $1(1.1)$ \\
Tuberous sclerosis & $1(1.1)$ \\
\hline
\end{tabular}

Data presented as $n$ (\%) unless indicated otherwise

endoscopies were performed by the same endoscopist (RS). Data were available for 40 of 54 (74\%) patients who underwent esophageal biopsies; gastric biopsy data were available for 54 patients $(100 \%)$ and duodenal biopsy results were available for 52 of 54 (96\%) patients. All biopsy results were reviewed by a senior pathologist. The present study obtained ethics committee approval before its commencement.

\section{RESULTS}

The charts of 94 patients with halitosis as their primary or secondary complaint were examined. Patient demographics and their comorbidities are presented in Table 1. One-third of the patients had comorbidities that were mainly ear nose and throat (ENT) problems, iron deficiency anemia and asthma.

Table 2 summarizes additional complaints of the patients in the present cohort. The most common additional symptom was abdominal pain (58 patients [61.7\%]). This was followed by symptoms suggestive of reflux (37 patients [39.4\%]) and nausea and/or vomiting (20 patients [21.3\%]). Sixteen patients (17\%) had no other complaints.

Fifty-eight patients (61.7\%) underwent upper endoscopy. The results of the endoscopies and biopsies are summarized in Table 3. Four patients who had recurrent halitosis and underwent repeated endoscopies are discussed separately. Pathology of any kind on upper gastrointestinal endoscopy was found in 41 patients $(75.9 \%)$; esophageal pathology was noted in 10 patients (18.5\%, mostly esophagitis); gastric pathology was noted in 36 patients $(66.7 \%$, mostly gastritis: $14 \mathrm{H}$ pylori positive and $22 \mathrm{H}$ pylori negative); and duodenal pathology was noted in 13 patients (24.1\%, mainly duodenitis).
TABLE 2

Additional complaints $(n=94)$

\begin{tabular}{lc}
\hline Complaint & $\mathbf{n}(\%)$ \\
\hline Abdominal pain & $58(61.7)$ \\
Heartburn/regurgitation/water brash* & $24(25.5)$ \\
Nausea/vomiting & $20(21.3)$ \\
Decreased appetite/weight loss & $13(13.8)$ \\
Constipation/encopresis & $8(8.5)$ \\
Dysphagia/odynophagia* & $6(6.4)$ \\
Flatulence & $6(6.4)$ \\
Diarrhea & $5(5.3)$ \\
Chest/retrosternal pain/discomfort* & $4(4.3)$ \\
Distended abdomen & $2(2.1)$ \\
Burping/hiccups* & $2(2.1)$ \\
Fever & $2(2.1)$ \\
Weakness & $1(1.1)$ \\
Aphthous ulcers & $1(1.1)$ \\
Hoarseness* & $1(1.1)$ \\
None & $16(17)$ \\
\hline
\end{tabular}

*Possible reflux symptoms

Biopsy results were available for most endoscopies. Esophageal biopsy results were available for 40 of 54 (74.1\%) endoscopies (esophageal biopsies were always taken if pathology was found). Abnormal findings (esophagitis) were present in 13 patients (32.5\%). Gastric biopsies were available for all patients. Abnormal findings (mainly gastritis) were found in 39 patients $(72.2 \%)$. An additional four patients were found to be $H$ pylori positive. Duodenal biopsy results were available for 52 of $54(96.3 \%)$ patients. Pathology was observed in 10 patients (18.5\%, mainly duodenitis).

Fifty-six patients $(59.6 \%)$ underwent recent examination by a dental surgeon, with pathology (eg, cavities) found in one patient $(1.8 \%)$. Thirty-three patients (59\%) underwent upper endoscopy, most of whom had abnormal macroscopic $(76 \%)$ and microscopic (85\%) findings (Table 4). Endoscopy was not performed in the patient who had cavities. Of the 27 patients (28.7\%) who were assessed by an ENT surgeon, pathology was found in six patients (two had enlarged tonsils, two had redness of the arytenoids, one had an enlarged adenoid and one had sinusitis). Of the five patients who underwent upper endoscopy, two (40\%) had macroscopic findings, and all five (100\%) had microscopic findings (Table 4). Endoscopic findings included hiatal hernia and $\mathrm{H}$ pylori-negative gastritis in one patient, and erythematous gastric mucosa in another. The biopsy results for these patients suggested esophagitis with acute focal duodenitis and chronic gastritis, respectively. The biopsy results for the patients who had normal endoscopy results $(n=3)$ were mild chronic gastritis, mild chronic esophagitis with mild chronic gastritis, and esophagitis. These three patients were treated with a proton pump inhibitor (PPI). Two of these patients showed some improvement, while no information was available for the third patient. Two patients were not treated, one showed some improvement, while the other had no improvement. Twenty-two patients (23.4\%) underwent both examinations. No differences were noted when an assessment of the diagnostic yield of abnormal endoscopic findings in relation to previous dental surgery or ENT surgeon assessment was performed (Table 4). 
TABLE 3

Endoscopy and biopsy findings

\begin{tabular}{|c|c|c|}
\hline & Endoscopy & Biopsy \\
\hline Esophagus & $n=54^{*}$ & $\mathrm{n}=40^{*}$ \\
\hline Normal & $44(81.5)$ & $26(65)$ \\
\hline Esophagitis & 6 (11.1) & $13(32.5)$ \\
\hline Hiatal hernia & $1(1.9)$ & - \\
\hline Esophagitis + hiatal hernia & $3(5.6)^{\dagger}$ & - \\
\hline Eosinophilic esophagitis & - & $1(2.5)$ \\
\hline Stomach & $n=54^{*}$ & $n=54^{*}$ \\
\hline Normal & $18(33.3)$ & $15(27.8)$ \\
\hline Helicobacter pylori positive & $14(25.9)$ & - \\
\hline Gastritis & $6(11.1)$ & $18(33.3)$ \\
\hline Erosions/ulcer & $1(1.9)$ & - \\
\hline Gastritis + erosions/ulcer & $5(9.3)$ & - \\
\hline Nodularity of antrum & $2(3.7)$ & - \\
\hline Helicobacter pylori negative & $22(40.7)$ & - \\
\hline Gastritis & $16(29.6)$ & $21(38.9)$ \\
\hline Erosions/ulcer & $0(0)$ & $1(1.8)$ \\
\hline Gastritis + erosions/ulcer & $4(7.4)$ & - \\
\hline Nodularity of antrum & $2(3.7)$ & - \\
\hline Focal foveolar hyperplasia & - & $1(1.9)$ \\
\hline Duodenum & $n=54^{*}$ & $n=52^{*}$ \\
\hline Normal & $41(75.9)$ & $42(80.8)$ \\
\hline Duodenitis & $5(9.3)$ & $9(17.3)$ \\
\hline Erosions & - & $1(1.9)$ \\
\hline Erosions/ulcer & $8(14.8)$ & - \\
\hline
\end{tabular}

Data presented as $n$ (\%). *Four patients whose halitosis recurred are not included; ${ }^{\dagger}$ One patient with suspected esophagitis

\section{TABLE 4}

Relationship between dental/ear, nose and throat (ENT) problems and gastrointestinal pathology in patients who underwent upper endoscopy $(n=55)$

\begin{tabular}{lcc}
\hline & \multicolumn{2}{c}{ Findings } \\
\cline { 2 - 3 } & Macroscopic & Microscopic \\
\hline Dental problem excluded $(n=33)$ & $25(75.8)$ & $28(84.8)$ \\
ENT problem excluded $(n=12)$ & $11(91.7)$ & $10(83.3)$ \\
Both dental + ENT problem excluded & $9(90)$ & $8(80)$ \\
$\quad(n=10)$ & & \\
No dental/ENT workup $(n=21)$ & $16(76.2)$ & $17(81)$ \\
ENT problem found $(n=5)$ & $2(40)$ & $5(100)$ \\
\hline
\end{tabular}

Data presented as $n$ (\%)

Fifty-two patients (57.8\%) were offered a treatment based on their endoscopic findings. Thirty-one of these patients (59.6\%) received PPI treatment, 18 patients $(34.6 \%)$ received $\mathrm{H}$ pylori eradication treatment (six also received treatment with a longer duration of PPIs), one patient (1.9\%) received $\mathrm{H}_{2}$-receptor blockers and two patients $(3.9 \%)$ received various treatments. Information regarding halitosis improvement was available for 74 of 90 patients ( $82.2 \%)$. Of these, nine patients (12.2\%) did not improve; some improvement was noted in 24 patients (32.4\%) and complete improvement was noted in 41 patients $(55.4 \%)$. Table 5 summarizes the response to the specific treatments.

There were no statistically significant differences between those who had complete resolution $(\mathrm{P}=0.98)$ and those who had any improvement $(\mathrm{P}=0.28)$ between the nontreated and treated groups.
TABLE 5

Improvement associated with treatment $(n=90)$ *

\begin{tabular}{lccccc}
\hline & & \multicolumn{4}{c}{ Improvement (n=74), n (\%) } \\
\cline { 3 - 6 } Treatment & $\mathbf{n}(\%)$ & None & Some & Complete Unknown \\
\hline No treatment & $38(42.2)$ & $5(13.2)$ & $7(18.4)$ & $15(39.5)$ & $11(28.9)$ \\
Treatment & $52(57.8)$ & $4(7.7)$ & $17(32.7)$ & $26(50)$ & $5(9.6)$ \\
PPI & $31(34.4)$ & $3(9.7)$ & $12(38.7)$ & $12(38.7)$ & $4(12.9)$ \\
Triple therapy & $6(6.7)$ & 0 & $1(16.7)$ & $5(83.3)$ & 0 \\
Triple therapy & $12(13.3)$ & 0 & $3(25)$ & $8(66.7)$ & $1(8.3)$ \\
$\quad$ followed by PPI & & & & & \\
$\mathrm{H}_{2}$-blockers & $1(1.1)$ & 0 & 0 & $1(100)$ & 0 \\
Various treatments & $2(2.2)$ & $1(50)$ & $1(50)$ & 0 & 0 \\
Total & $90(100)$ & $9(10)$ & $24(26.7)$ & $41(45.5)$ & $16(17.8)$ \\
\hline
\end{tabular}

${ }^{*}$ Four patients whose halitosis recurred are not included. PPI Proton pump inhibitor

Of the 38 patients who were not treated, 30 did not undergo an endoscopy (13 patients improved, four improved somewhat, three showed no improvement and the outcome for 10 patients was unknown), three had normal endoscopy (one improved and two showed some improvement) and five patients had positive findings (one had mild esophagitis, two had mild esophagitis and mild $\mathrm{H}$ pylori-negative gastritis, and two patients had mild $H$ pylori-negative gastritis) (one patient improved, one patient showed some improvement, two patients showed no improvement and the outcome of one patient was unknown).

Halitosis symptoms recurred and endoscopies were repeated in four patients. All four patients were found to have gastrointestinal pathology during both presentations. In the first endsocopy, macroscopic pathology was found in three patients: two patients had esophageal pathology (hiatal hernia) and three patients had gastric pathology (mostly gastritis, one patient was $H$ pylori positive). On biopsy, one patient had esophagitis and duodenitis, one patient had $\mathrm{H}$ pylori-positive gastritis and lymphangiectasia was suspected in one patient. All patients received treatment (three patients received PPI; of these three, one received eradication therapy and PPI) and improvement was noted; however, halitosis symptoms recurred. In the second endoscopy, which was performed after symptoms recurred, macroscopic pathology was found in all four patients: three patients had esophageal pathology (one hiatal hernia, one had esophagitis and one had esophageal ulcers), all patients had gastric pathology ( $H$ pylori-negative gastritis), and two patients had duodenal pathology (duodenal ulcers). On biopsy, two patients had esophagitis (one with a hyperplastic polyp), two patients had $\mathrm{H}$ pylori-negative gastritis, and one patient had duodenitis. All four patients received PPI treatment. One patient improved completely, while two patients had some improvement and one patient was lost to follow-up.

\section{DISCUSSION}

Halitosis is very common and may be lead to a significant social or psychological handicap. The reported prevalence of halitosis ranges from $8 \%$ to $45.7 \%$ of the general population $(2,26-28)$. Different conditions have been implicated, such as local factors of pathological origin (eg, periodontal pockets, stomatitis, rhinitis, pharyngitis and tumours); local factors of nonpathological origin (eg, lack of self-clearing agents, smoking and food debris); systemic factors of pathological origin 
(eg, diabetes, liver and kidney failure, and lung infections); systemic factors of nonpathological origin (metabolites of ingested foods such as garlic and onions excreted by the lung); and systemic administration of drugs (1). The gastrointestinal aspects of halitosis are generally overlooked in the literature.

Halitosis is associated with volatile sulphur compounds such as hydrogen sulphide, methyl mercaptan and dimethyl sulphide $(3,29)$, while other components such as cadaverine, indole and skatole may also be involved (3). Lee et al (30) studied the ability of $\mathrm{H}$ pylori to produce volatile sulphur compounds in vitro. They found that $H$ pylori produced hydrogen sulphide and methyl mercaptan - both gases that can contribute to halitosis. Interestingly, the ability to produce either of these gases was strain specific. Ierardi et el (1) studied the association of objective halitosis (sulphide levels in the breath) with the presence of $H$ pylori and the effect of eradication therapy. They found that in 19 of the 30 subjects, successful $H$ pylori eradication therapy resulted in a decrease of sulphide levels to below the cut-off value in 15 patients (79\%). In the other 11 subjects, in whom $\mathrm{H}$ pylori positivity persisted, halitosis parameters did not change. Objective halitosis disappeared in nine patients only after they underwent another $\mathrm{H}$ Pylori eradication treatment.

Using biopsies and molecular methods, Adler et al (8) showed evidence of the presence of $H$ pylori in the oral cavity of $87 \%$ of patients with halitosis and lingual hyperplasia. However, another study (19) failed to detect higher levels of $H$ pylori DNA in the saliva of patients complaining of halitosis.

Several articles have reported an improvement of halitosis symptoms after eradication treatment for $H$ pylori. Tiomny et al (14) were the first to report improvement of halitosis after successful eradication treatment for Helicobacter. Serin et al (12) demonstrated an improvement of halitosis in $\mathrm{H}$ pylori-positive patients with nonulcer dyspepsia, with a decrease from $61.5 \%$ to $12.8 \%$ after eradication therapy $(2.7 \%$ after successful eradication treatment). Shashidhar et al (16) reported a decrease in halitosis symptoms from $45 \%$ to $22.6 \%$ in pediatric patients after $H$ pylori eradication treatment. Finally, Katsinelos et al (20) showed a significant decrease of halitosis symptoms from $100 \%$ to $11.2 \%$ after eradication treatment for $\mathrm{H}$ pylori.

GERD is another condition that has been associated with halitosis. Poelmans et al (22) showed a higher prevalence of erosive esophagitis $(52.3 \%$ versus $38.4 \% ; \mathrm{P}<0.05$ [mainly grade $1: 31.9 \%$ versus $22.7 \% ; \mathrm{P}<0.05])$ and peptic ulcer $(8.4 \%$ versus $4.3 \% ; \mathrm{P}<0.05)$ in patients with GERD-related ENT symptoms (including halitosis) compared with typical GERD patients. Di Fede et al (24) studied 200 patients with GERD and 100 matched healthy controls. They found that halitosis was significantly more common in patients with GERD than in control subjects $(49.2 \%$ versus $31 \%$; $\mathrm{P}=0.0004)$.

A recent study by Moshkowitz et al (25) evaluated the relationship between upper gastrointestinal conditions, especially GERD, and halitosis in 132 consecutive patients complaining of upper gastrointestinal symptoms. All patients completed a validated questionnaire that was designed to characterize and measure the severity of their symptoms. They found that halitosis was significantly associated with the occurrence and severity of heartburn $(\mathrm{P}=0.027)$, regurgitation $(\mathrm{P}=0.002)$, sour taste $(\mathrm{P}<0.001)$, belching $(\mathrm{P}=0.001)$ and borborygmus $(\mathrm{P}=0.006)$. Halitosis was not associated with upper abdominal pain, bloating, early satiety or chest pain. Regarding the final diagnosis, halitosis was significantly associated with GERD $(\mathrm{P}=0.002)$, but not with functional dyspepsia $(\mathrm{P}=0.855)$ or peptic ulcer disease $(\mathrm{P}=0.765)$. Interestingly, no correlation was found between $H$ pylori infection status and halitosis occurrence and severity. Symptoms characteristic of GERD were present in 37 of our 94 patients (39.4\%).

We found that gastrointestinal pathology was very common in patients with halitosis and was present in 54 of the 94 patients (57.4\%). Pathology was noted regardless of dental or otolaryngological findings. Most pathologies, both macroscopic and microscopic, were noted in the stomach (60\% non- $H$ pylori related), followed by the duodenum and the esophagus.

We found that most patients improved with treatment (mainly PPI and/or $\mathrm{H}$ pylori eradication treatment). The improvement with antibiotic treatment may have been the result of compositional changes in the mouth flora. Nevertheless, the fact that many patients without $H$ pylori infection responded to PPI treatment may also suggest a relationship between non-H pylori gastrointestinal pathologies and halitosis.

There is little doubt that gastrointestinal-associated halitosis is not rare as previously believed. Gastrointestinal etiology should be investigated after ruling out other etiologies by careful dental surgeon and ENT surgeon assessment, or when other upper gastrointestinal symptoms are present. Further large prospective studies are required to confirm this association.

\section{REFERENCES}

1. Ierardi E, Amoruso A, La NT, et al. Halitosis and Helicobacter pylori: A possible relationship. Dig Dis Sci 1998;43:2733-7.

2. Kanehira T, Takehara J, Takahashi D, Honda O, Morita M. Prevalence of oral malodor and the relationship with habitual mouth breathing in children. J Clin Pediatr Dent 2004;28:285-8.

3. Amir E, Shimonov R, Rosenberg M. Halitosis in children. J Pediatr 1999;134:338-43.

4. Rosenberg M. Clinical assessment of bad breath: Current concepts. J Am Dent Assoc 1996;127:475-82.

5. Warren JR, Marshall B. Unidentified curved bacilli on gastric epithelium in active chronic gastritis. Lancet 1983;1:1273-5.

6. Sherman P, Czinn S, Drumm B, et al. Helicobacter pylori infection in children and adolescents: Working Group Report of the First World Congress of Pediatric Gastroenterology, Hepatology, and Nutrition. J Pediatr Gastroenterol Nutr 2002;35(Suppl 2):S128-S133.

7. Suerbaum S, Michetti P. Helicobacter pylori infection. N Engl J Med 2002;347:1175-86.

8. Adler I, Denninghoff VC, Alvarez MI, Avagnina A, Yoshida R, Elsner B. Helicobacter pylori associated with glossitis and halitosis. Helicobacter 2005;10:312-7.

9. Hoshi K, Yamano Y, Mitsunaga A, Shimizu S, Kagawa J, Ogiuchi H. Gastrointestinal diseases and halitosis: Association of gastric Helicobacter pylori infection. Int Dent J 2002;52(Suppl 3):207-11.

10. Marshall BJ, Armstrong JA, McGechie DB, Glancy RJ. Attempt to fulfil Koch's postulates for pyloric Campylobacter. Med J Aust 1985;142:436-9.

11. Schubert TT, Schubert AB, Ma CK. Symptoms, gastritis, and Helicobacter pylori in patients referred for endoscopy. Gastrointest Endosc 1992;38:357-60.

12. Serin E, Gumurdulu Y, Kayaselcuk F, Ozer B, Yilmaz U, Boyacioglu S. Halitosis in patients with Helicobacter pylori-positive non-ulcer dyspepsia: An indication for eradication therapy? Eur J Intern Med 2003;14:45-8.

13. Sherman PM, Lin FY. Extradigestive manifestation of Helicobacter pylori infection in children and adolescents. Can J Gastroenterol 2005;19:421-4.

14. Tiomny E, Arber N, Moshkowitz M, Peled Y, Gilat T. Halitosis and Helicobacter pylori. A possible link? J Clin Gastroenterol 1992;15:236-7.

15. Gasbarrini A, Ojetti V, Pitocco D, et al. Helicobacter pylori infection in patients affected by insulin-dependent diabetes mellitus. Eur J Gastroenterol Hepatol 1998;10:469-72. 
16. Shashidhar H, Peters J, Lin CH, Rabah R, Thomas R, Tolia V. A prospective trial of lansoprazole triple therapy for pediatric Helicobacter pylori infection. J Pediatr Gastroenterol Nutr 2000;30:276-82.

17. Candelli M, Rigante D, Marietti G, et al. Helicobacter pylori, gastrointestinal symptoms, and metabolic control in young type 1 diabetes mellitus patients. Pediatrics 2003;111:800-3.

18. Werdmuller BF, van der Putten TB, Balk TG, Lamers CB, Loffeld RJ. Clinical presentation of Helicobacter pylori-positive and -negative functional dyspepsia. J Gastroenterol Hepatol 2000;15:498-502.

19. Suzuki N, Yoneda M, Naito T, et al. Detection of Helicobacter pylori DNA in the saliva of patients complaining of halitosis. J Med Microbiol 2008;57:1553-9.

20. Katsinelos P, Tziomalos K, Chatzimavroudis G, et al. Eradication therapy in Helicobacter pylori-positive patients with halitosis: Long-term outcome. Med Princ Pract 2007;16:119-23.

21. Carr MM, Nguyen A, Nagy M, Poje C, Pizzuto M, Brodsky L. Clinical presentation as a guide to the identification of GERD in children. Int J Pediatr Otorhinolaryngol 2000;54:27-32.

22. Poelmans J, Feenstra L, Demedts I, Rutgeerts P, Tack J. The yield of upper gastrointestinal endoscopy in patients with suspected reflux-related chronic ear, nose, and throat symptoms. Am J Gastroenterol 2004;99:1419-26.
23. DeVault KR. Should upper gastrointestinal endoscopy be part of the evaluation for supraesophageal symptoms of GERD? Am J Gastroenterol 2004;99:1427-9.

24. Di Fede O, Di Liberto C, Occhipinti G, et al. Oral manifestations in patients with gastro-oesophageal reflux disease: A single-center case-control study. J Oral Pathol Med 2008;37:336-40.

25. Moshkowitz M, Horowitz N, Leshno M, Halpern Z. Halitosis and gastroesophageal reflux disease: A possible association. Oral Dis 2007;13:581-5.

26. Iwanicka-Grzegorek E, Michalik J, Kepa J, Wierzbicka M, Aleksinski M, Pierzynowska E. Subjective patients' opinion and evaluation of halitosis using halimeter and organoleptic scores. Oral Dis 2005;11(Suppl 1):86-8.

27. Levin L, Rosenberg M. Oral hygiene, caries status and bad breath among young Israeli recruits. Refuat Hapeh Vehashinayim 2005;22:27-31.

28. Miyazaki H, Sakao S, Katoh Y, Takehara T. Correlation between volatile sulphur compounds and certain oral health measurements in the general population. J Periodontol 1995;66:679-84.

29. Tonzetich J. Direct gas chromatographic analysis of sulphur compounds in mouth air in man. Arch Oral Biol 1971;16:587-97.

30. Lee H, Kho HS, Chung JW, Chung SC, Kim YK. Volatile sulfur compounds produced by Helicobacter pylori. J Clin Gastroenterol 2006;40:421-6. 


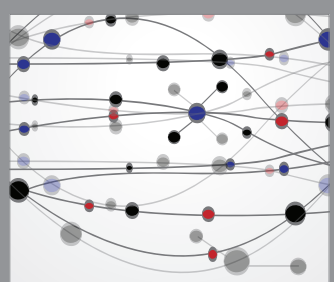

The Scientific World Journal
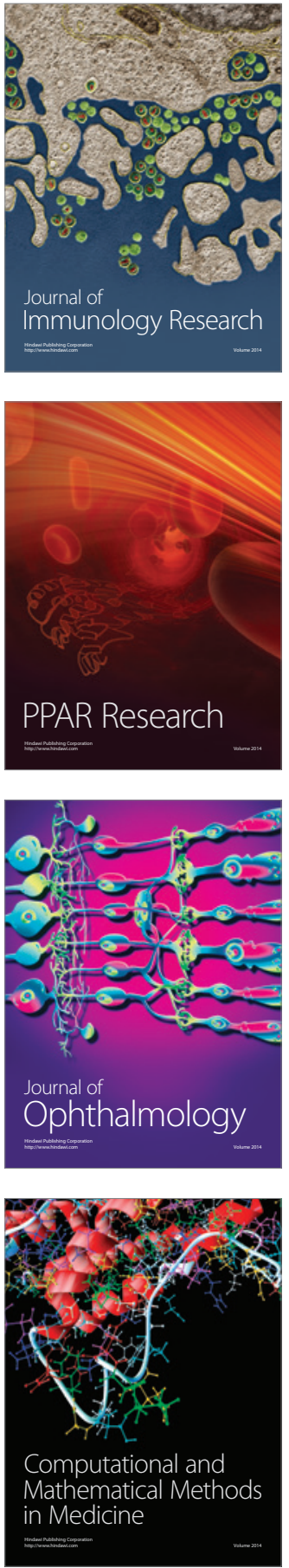

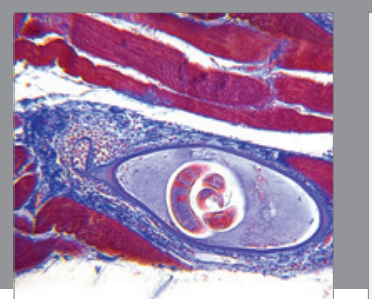

Gastroenterology Research and Practice

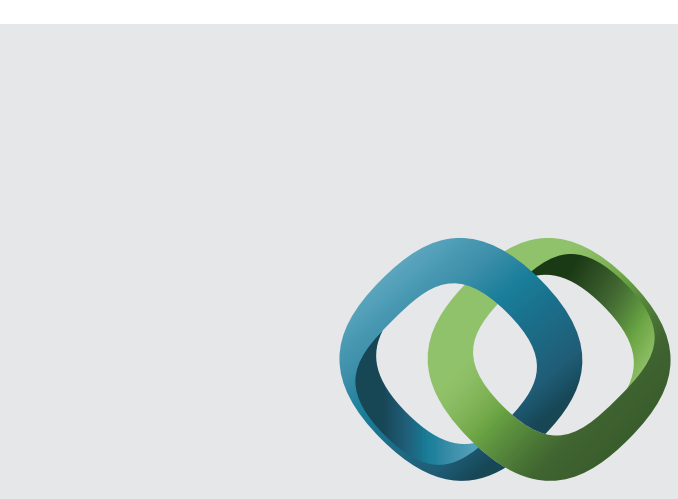

\section{Hindawi}

Submit your manuscripts at

http://www.hindawi.com
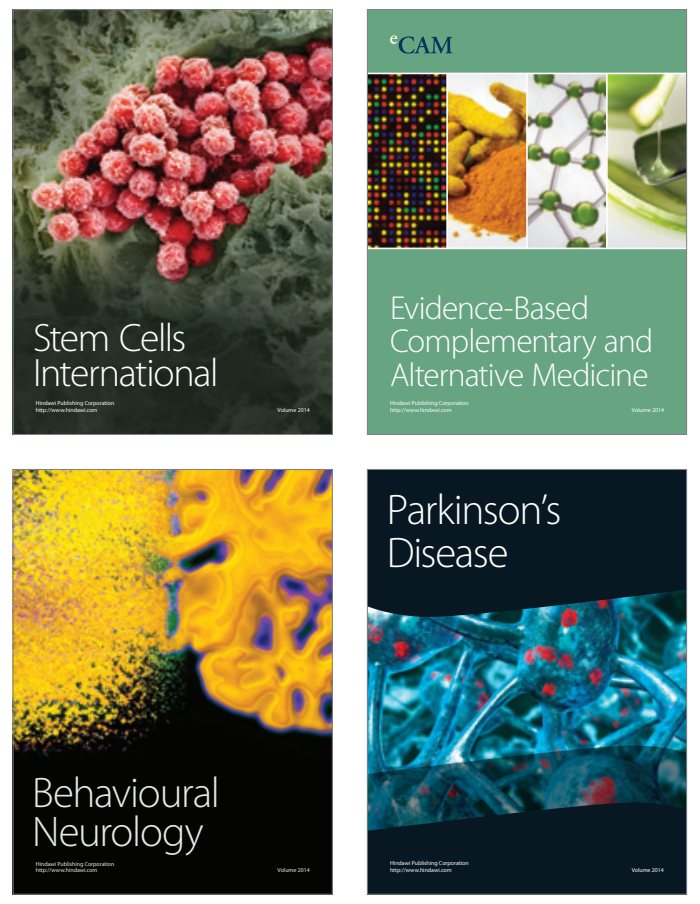
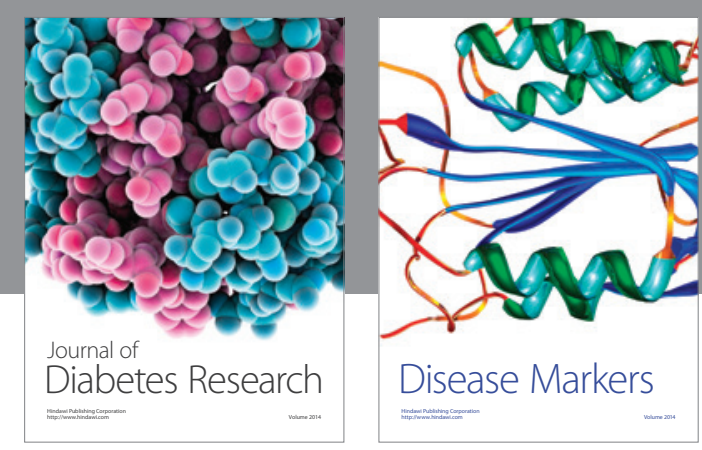

Disease Markers
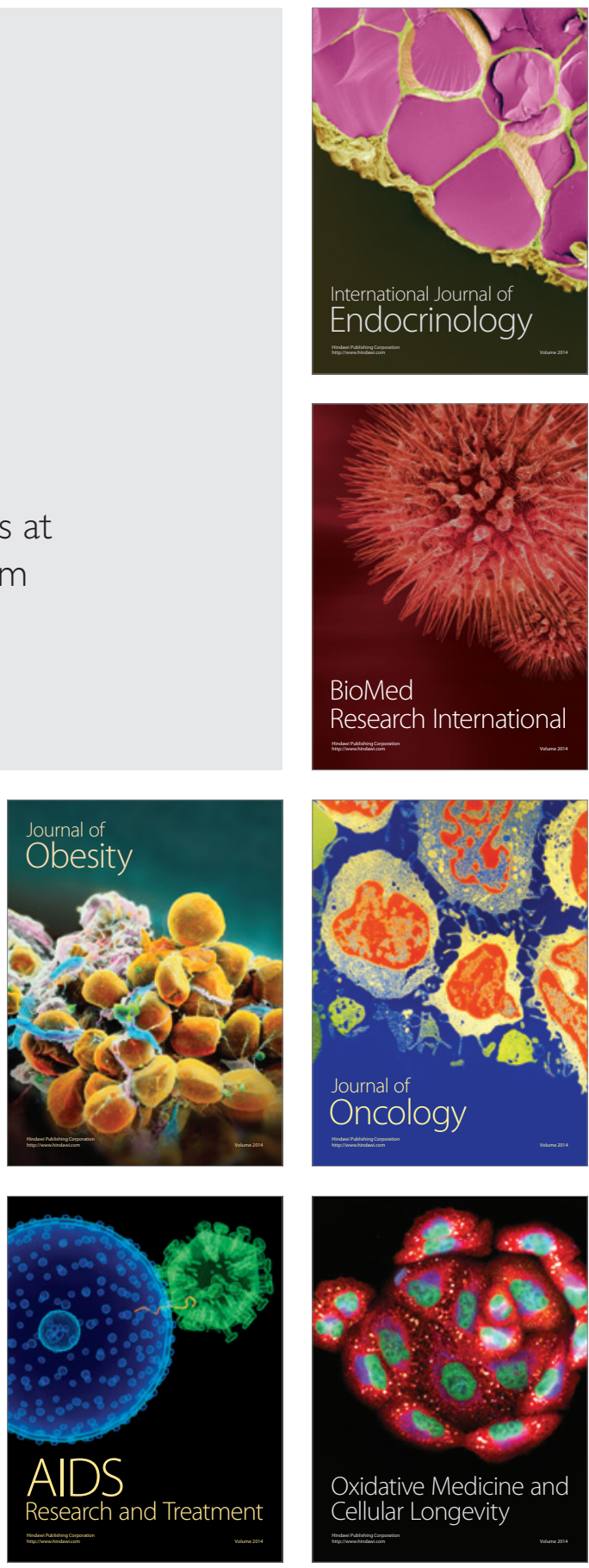